\title{
Atlantoaxial Stabilization Using C1 and C2 Laminar Screw Fixation
}

\author{
Takashi Tsuji ${ }^{1,2}$, Kazuhiro Chiba ${ }^{1}$, Yosuke Horiuchi ${ }^{1}$, Tadahisa Urabe ${ }^{3}$, Shota Fujita ${ }^{3}$, Morio Matsumoto $^{2}$ \\ ${ }^{1}$ Department of Orthopaedic Surgery, Kitasato University Kitasato Institute Hospital, Tokyo, Japan \\ ${ }^{2}$ Department of Orthopaedic Surgery, School of Medicine, Keio University, Tokyo, Japan \\ ${ }^{3}$ Department of Orthopaedic Surgery, Ashikaga Red Cross Hospital, Tochigi, Japan
}

We describe the use of a C1 laminar screw in combination with a C2 laminar screw as a salvage technique to treat two patients, one with persistent first intersegmental artery and the other with vertebral artery occlusion after cervical spine fracture. The combined use of $\mathrm{C} 1$ and $\mathrm{C} 2$ laminar screws allows for good fixation of the atlantoaxial joint with a lower risk of vertebral artery injury; therefore, it can be an alternative surgical procedure for patients with congenital or traumatic anomalous vertebral artery.

Keywords: Persistent first intersegmental artery; Vertebral artery occlusion; Vertebral artery injury; C1 laminar screw

\section{Introduction}

Conventional methods used for $\mathrm{C} 1$ posterior fixation include posterior wiring [1,2], transarticular screws [3], and pedicle or lateral mass screws [4,5]. Recently, the use of wiring or hooks has been replaced by that of screws, which provide immediate stability and an excellent fusion rate [5]. However, screw fixation is associated with an increased risk of vertebral artery (VA) injury, especially in patients in whom the VA is found at an anomalous location. Moreover, in patients with a unilateral VA occlusion, the contralateral VA must be preserved to avoid severe complications such as medullary or cerebellar infarction associated with VA injury [6].

Here we describe a technique using a C1 laminar screw in combination with a $\mathrm{C} 2$ laminar screw as a salvage technique to treat two patients, one with an anomalous VA (persistent first intersegmental artery) and the other with a VA occlusion after cervical spine fracture.

\section{Technical Note}

The patient was placed in the prone position under general anesthesia and cervical alignment was maintained in a neutral position using a skull clamp. A midline subperiosteal exposure of the $\mathrm{C} 1$ and $\mathrm{C} 2$ posterior elements was performed. C1 lateral mass and C2 pedicle screws were unilaterally placed using standard anatomic landmarks under fluoroscopic guidance. Subsequently, the ipsilateral C2 laminar screw was inserted. Finally, the C1 laminar screw was placed. A 3.0- $\mathrm{mm}$ high-speed bur was used to make an entry point over the posterior tubercle of the $\mathrm{C} 1$ posterior arch. The probe was inserted gradually without fluoroscopic guidance through the medullary core to a depth determined based on the preoperative computed tomography (CT) scan. The hole was tapped using a 3.5$\mathrm{mm}$ tap, and a $3.5-\mathrm{mm}$ multiaxial screw of the same size was inserted into the $\mathrm{C} 1$ laminae because the dorsal cortex of the $\mathrm{C} 1$ lamina is usually thin and easy to destroy during

\footnotetext{
Received Aug16, 2016; Revised Sep 17, 2016; Accepted Oct 2, 2016

Corresponding author: Takashi Tsuji

Department of Orthopaedic Surgery, Kitasato University Kitasato Institute Hospital,

5-9-1 Shirokane, Minato, Tokyo, 108-8642, Japan

Tel: +81-33444-6161, Fax: +81-3-3448-0553, E-mail: tsuji9@gmail.com
} 
screw insertion. After the rod was secured to the screw heads, an autologous iliac bone graft was placed over the decorticated $\mathrm{C} 1$ arch and C2 lamina. Postoperatively, the patients were immobilized using a hard cervical orthosis for 3 months.

Using unilateral $\mathrm{C} 1$ and $\mathrm{C} 2$ laminar screws in combination with ipsilateral $\mathrm{C} 1$ and $\mathrm{C} 2$ pedicle screws, this technique provides immediate stability and can minimize the risk of contralateral VA injury (Fig. 1).

\section{Case 1}

A 64-year-old female presented with a 5-year history of sensory disturbance and clumsiness of both hands. Physical examination revealed hyperreflexia and muscle weakness in the upper extremities. Plain radiographs and CT scans revealed os odontoideum with C1-2 instability, and magnetic resonance imaging (MRI) showed a highsignal-intensity zone in the spinal cord (Fig. 2A). MR angiography showed that the right VA, the appearance of which dominated that of the left VA, was at an anomalous location (persistent first intersegmental artery; Fig. $2 \mathrm{~B})$. Therefore, we assumed that the insertion of a right C1 lateral mass screw would be unsafe and indicated left unilateral C1and C2 laminar screws in combination with ipsilateral (left) $\mathrm{C} 1$ lateral mass and $\mathrm{C} 2$ pedicle screws to avoid injury to the right VA (Fig. 3A, B). Postoperative plain flexion/extension radiographs and CT scans (Fig. 3C) showed evidence of a solid bony fusion without implant loosening at 6 months after surgery.

\section{Case 2}

A 16-year-old female was involved in a traffic accident.
She suffered a head injury that required a craniotomy. During rehabilitation, she was subsequently noted to have torticollis due to traumatic atlantoaxial rotatory fixation. CT scans and CT angiograms revealed that the groove for the left VA in C2 was occupied by a bony fragment, causing
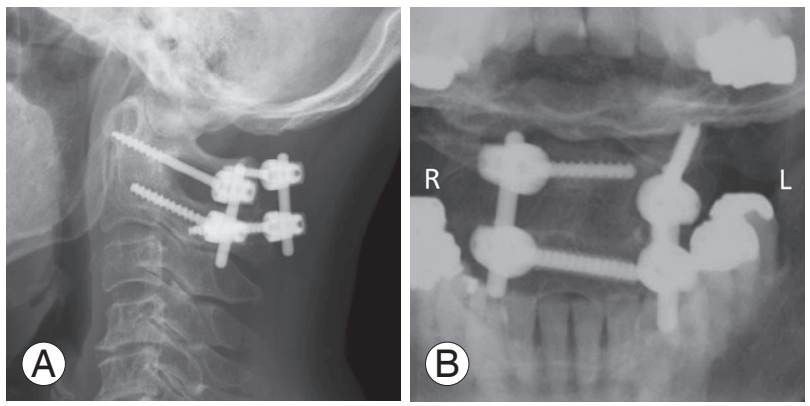

Fig. 1. Postoperative plain radiographs showing solid bony union without screw loosening at the final follow-up (A), (B). Note that the risk of right vertebral artery (VA) injury is almost nonexistent because the trajectories of the screws are far removed from the course of the right VA.
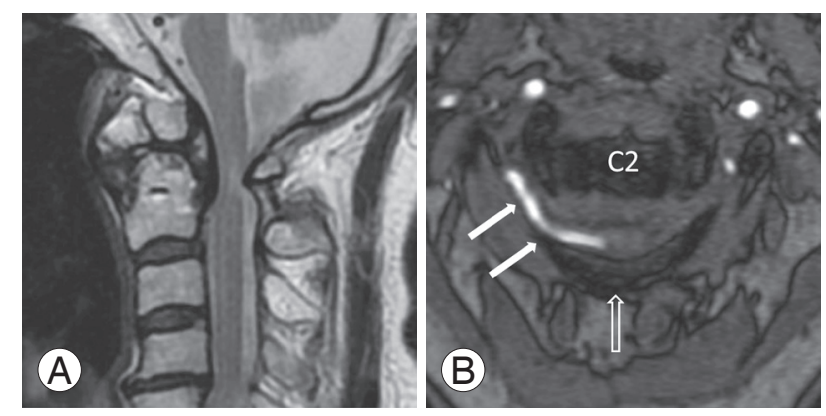

Fig. 2. Magnetic resonance imaging (MRI) showing os odontideum and signal intensity changes in the spinal cord (A). Magnetic resonance angiogram (B) showing anomalous vertebral artery (white arrows; persistent first intersegmental artery) coursing through the C1-2 neural foramina in the anatomic region normally occupied by the $\mathrm{C} 2$ nerve root. Open arrow shows posterior arch of $\mathrm{C} 1$.
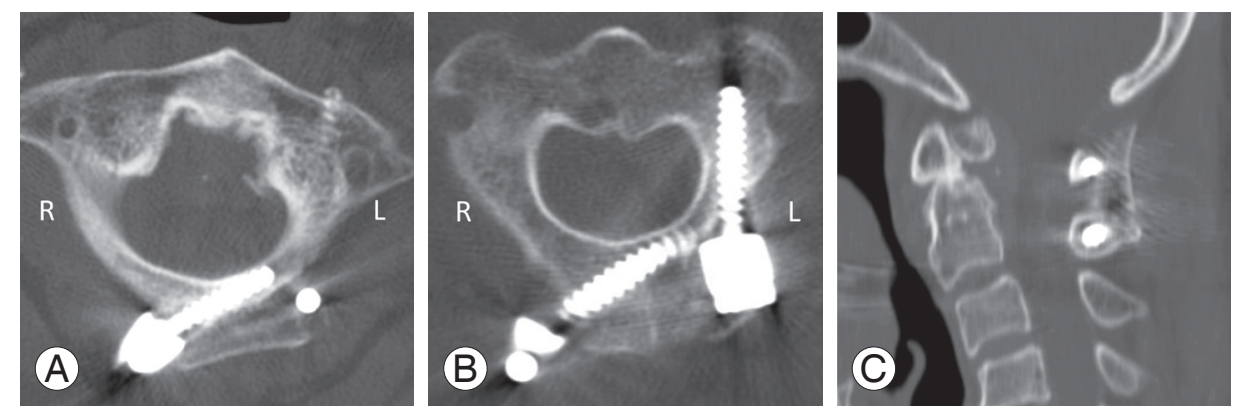

Fig. 3. Postoperative computed tomography images show left C1 laminar screw ( $3.5 \mathrm{~mm} \times 20 \mathrm{~mm}$ ) (A), C2 laminar and pedicle screws (B), and autologous bone graft (C). Note that the trajectories of the screws are far removed from the course of the right vertebral artery. 
left VA occlusion (Fig. 4). To avoid injury to the right VA, which would potentially be fatal, we indicated left $\mathrm{C} 1$ and C2 laminar screws in combination with ipsilateral (left) $\mathrm{C} 1$ lateral mass and $\mathrm{C} 2$ pedicle screws (Fig. 5A). Plain flexion-extension radiographs and CT scans (Fig. 5B) showed evidence of solid bony fusion at 6 months after surgery.

Informed consent was obtained from both patients and the parents of the patient in case 2 to publish their clinical data and accompanying images.
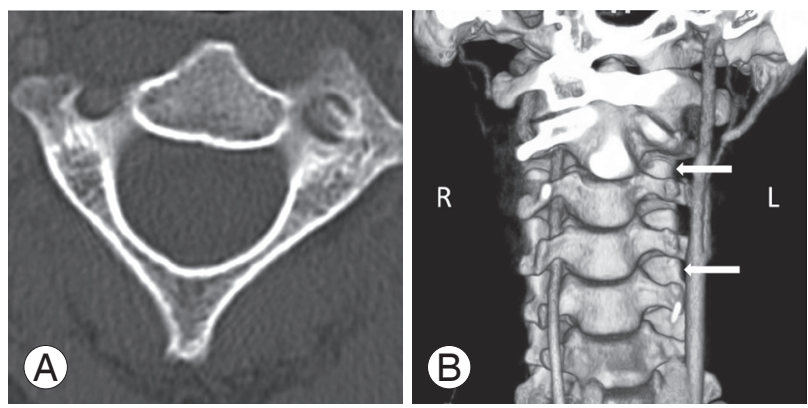

Fig. 4. Axial computed tomography (CT) image showing left vertebral artery (VA) groove occupied by a bony fragment (A). Reconstruction of CT angiogram (B) shows occlusion of the left VA (white arrows).
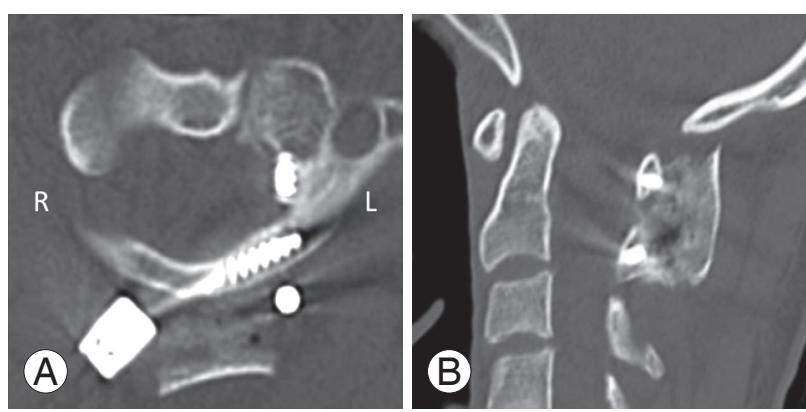

Fig. 5. Postoperative computed tomography showing C1 laminar screw (3.5 mm×28 mm, partially threaded), which remains intraosseous (A), and solid bone fusion (B).

\section{Discussion}

$\mathrm{C} 1$ lateral mass and $\mathrm{C} 2$ pedicle or pars screw fixation, first reported by Goel and Laheri [4] and later popularized by Harms and Melcher [5], is now considered as one of the most robust constructs for fixation of the atlantoaxial joint. However, the implantation of lateral mass screws, pedicle screws, or both is also technically demanding because of the complicated anatomy in the vicinity of the atlas and axis, and the potential risk of catastrophic VA injury during surgery. Although its rate of incidence is extremely low, VA injury could cause serious consequences including uncontrollable bleeding, pseudoaneurysm, cerebral ischemia, and death $[7,8]$.

Wright [9] proposed the use of C2 laminar screws, which was shown in a biomechanical study to provide stability equivalent to the use of $\mathrm{C} 2$ pedicle or pars screws [10]. Furthermore, C2 laminar screws have been shown to reduce the risk of VA injury as compared with $\mathrm{C} 2$ pedicle screws or pars screws. In fact, Parker et al. [11] noted that laminar screws have a significantly smaller risk of radiographic breach than do $\mathrm{C} 2$ pedicle screws. Currently, laminar screws are also used for fixation of the subaxial cervical spine, thoracic spine, and lumbar spine [12-14]. However, reports describing the use of laminar screws in the atlas are limited (Table 1). Donnellan et al. [15] described three successful cases in which bilateral C1 laminar screws were used for bony abnormality. Subsequently, Baaj and Vrionis [16] and Yew et al. [17] also reported the successful use of unilateral or bilateral C1 laminar screws.

To our knowledge, this report is the first to use $\mathrm{C} 1$ laminar screws for patients with a persistent first intersegmental artery or a unilateral VA occlusion. We also indicated the use of a C2 laminar screw in combination with a C1 laminar screw to further minimize the risk of VA injury.

Table 1. Case reports utilizing C1 laminar screws

\begin{tabular}{|c|c|c|c|c|c|}
\hline Study & Case & Diagnosis & Anatomical characteristics & C1 anchor & C2 anchor \\
\hline Donnellan et al. [15] & 3 & $\begin{array}{l}\text { Osteoarthritis } \\
\text { Osteoarthritis } \\
\text { Trauma }\end{array}$ & $\begin{array}{l}\text { Erosion of C1 LM } \\
\text { Erosion of C1 LM } \\
\text { Bifid of C1 posterior arch }\end{array}$ & Bil. LS & Bil. Pars screw \\
\hline Baaj et al. [16] & 1 & Tumor & Tumor invasion to C1 LM & LS+LMS & Bil. Pars screw \\
\hline Yew et al. [17] & 1 & Os odontoideum & Anomalous VA (details unknown) & Bil. LS & Bil. LS \\
\hline Present study & 2 & $\begin{array}{l}\text { Os odontoideum } \\
\text { Trauma }\end{array}$ & $\begin{array}{l}\text { Persistent first intersegmental artery } \\
\text { VA occlusion }\end{array}$ & LS+LMS & $\mathrm{LS}+\mathrm{PS}$ \\
\hline
\end{tabular}

LM, lateral mass; Bil, bilateral; LS, laminar screw; LMS, lateral mass screw; VA, vertebral artery; PS, pedicle screw. 
Although, Yeom et al. [18] reported that routine insertion of $\mathrm{C} 1$ lateral mass screws was feasible even in patients with a persistent first intersegmental artery, this technique still carries the risk of troublesome bleeding from the venous plexus [19], occipital neuralgia [20], and VA injury. Another strategy around this anatomy is the use of a transarticular screw, whereas the retrospective study demonstrated that-including both known and suspected cases-the risk of VA injury was $4.1 \%$ per patient or $2.2 \%$ per screw inserted [6]. However, insertion of a C1 laminar screw is straightforward and technically easier than insertion of lateral mass screws or transarticular screws without fluoroscopic guidance.

Recently, Jin et al. [21] described the results of biomechanical tests and anatomical measurements for the $\mathrm{C} 1$ laminar screw [22]. One study concluded that a combination of unilateral $\mathrm{C} 1$ and $\mathrm{C} 2$ laminar screws with ipsilateral $\mathrm{C} 1$ and $\mathrm{C} 2$ pedicle screws provides the same degree of immediate stability as does bilateral $\mathrm{C} 1$ and $\mathrm{C} 2$ pedicle screw fixation [22]. However, another study comparing a $\mathrm{C} 1$ laminar screw with a $\mathrm{C} 1$ lateral mass screw concluded that there were no significant differences in stability for flexion-extension and axial rotation, except for lateral bending [21]. Therefore, the stability of the $\mathrm{C} 1$ laminar screw and that of the $\mathrm{C} 1$ lateral mass screw are not completely equal. An anatomical assessment indicated that 93.4\% of the atlas posterior arch could hold $3.5 \mathrm{~mm}$ diameter screws [21]. Taken together with previous reports, these findings suggest that unilateral C1 and C2 laminar screw fixation could be an alternative salvage option for posterior atlantoaxial fixation, especially when the VA is anatomically anomalous or is injured on one side and thereby precludes safe placement of lateral mass screws or pedicle screws.

This technique would be unsuitable for patients with an aplastic or hypoplastic $\mathrm{C} 1$ posterior arch, severe osteoporosis, or previous $\mathrm{C} 1$ laminectomy. It also carries the potential risk of damaging the dura and spinal cord; therefore, the accuracy of the screw trajectory must be ensured to avoid breaching the wall of the $\mathrm{C} 1$ posterior arch.

In conclusion, the combined use of $\mathrm{C} 1$ and $\mathrm{C} 2$ laminar screws is a straight forward technique that allows for good fixation of the atlantoaxial joint with a lower risk of VA injury. As such, it is an efficient alternative option for patients with congenital or traumatic anomalies in the VA.

\section{Conflict of Interest}

No potential conflict of interest relevant to this article was reported.

\section{ORCID}

Takashi Tsuji: 0000-0002-0878-3623

\section{References}

1. Gallie WE. Fractures and dislocations of the cervical spine. Am J Surg 1936;46:495-9.

2. Brooks AL, Jenkins EB. Atlanto-axial arthrodesis by the wedge compression method. J Bone Joint Surg Am 1978;60:279-84.

3. Grob D, Magerl F. Surgical stabilization of C1 and C2 fractures. Orthopade 1987;16:46-54.

4. Goel A, Laheri V. Plate and screw fixation for atlantoaxial subluxation. Acta Neurochir (Wien) 1994;129: 47-53.

5. Harms J, Melcher RP. Posterior C1-C2 fusion with polyaxial screw and rod fixation. Spine (Phila $\mathrm{Pa}$ 1976) 2001;26:2467-71.

6. Wright NM, Lauryssen C. Vertebral artery injury in C1-2 transarticular screw fixation: results of a survey of the AANS/CNS section on disorders of the spine and peripheral nerves. American Association of Neurological Surgeons/Congress of Neurological Surgeons. J Neurosurg 1998;88:634-40.

7. Molinari R, Bessette M, Raich AL, Dettori JR, Molinari C. Vertebral artery anomaly and injury in spinal surgery. Evid Based Spine Care J 2014;5:16-27.

8. Peng CW, Chou BT, Bendo JA, Spivak JM. Vertebral artery injury in cervical spine surgery: anatomical considerations, management, and preventive measures. Spine J 2009;9:70-6.

9. Wright NM. Posterior C2 fixation using bilateral, crossing C2 laminar screws: case series and technical note. J Spinal Disord Tech 2004;17:158-62.

10. Gorek J, Acaroglu E, Berven S, Yousef A, Puttlitz CM. Constructs incorporating intralaminar C2 screws provide rigid stability for atlantoaxial fixation. Spine 2005;30:1513-8.

11. Parker SL, McGirt MJ, Garces-Ambrossi GL, et al. Translaminar versus pedicle screw fixation of $\mathrm{C} 2$ : comparison of surgical morbidity and accuracy of 
313 consecutive screws. Neurosurgery 2009;64:343-8.

12. Hong JT, Sung JH, Son BC, Lee SW, Park CK. Significance of laminar screw fixation in the subaxial cervical spine. Spine (Phila Pa 1976) 2008;33:1739-43.

13. Kretzer RM, Sciubba DM, Bagley CA, Wolinsky JP, Gokaslan ZL, Garonzik IM. Translaminar screw fixation in the upper thoracic spine. J Neurosurg Spine 2006;5:527-33.

14. Aepli M, Mannion AF, Grob D. Translaminar screw fixation of the lumbar spine: long-term outcome. Spine (Phila Pa 1976) 2009;34:1492-8.

15. Donnellan MB, Sergides IG, Sears WR. Atlantoaxial stabilization using multiaxial C-1 posterior arch screws. J Neurosurg Spine 2008;9:522-7.

16. Baaj AA, Vrionis FD. Atlantoaxial stabilization utilizing atlas translaminar fixation. J Clin Neurosci 2010; 17:1578-80.

17. Yew A, Lu D, Lu DC. CT-based morphometric analysis of C1 laminar dimensions: C1 translaminar screw fixation is a feasible technique for salvage of atlanto- axial fusions. Surg Neurol Int 2015;6:S236-9.

18. Yeom JS, Kafle D, Nguyen NQ, et al. Routine insertion of the lateral mass screw via the posterior arch for $\mathrm{C} 1$ fixation: feasibility and related complications. Spine J 2012;12:476-83.

19. Pan J, Li L, Qian L, Tan J, Sun G, Li X. C1 lateral mass screw insertion with protection of $\mathrm{C} 1-\mathrm{C} 2$ venous sinus: technical note and review of the literature. Spine (Phila Pa 1976) 2010;35:E1133-6.

20. Rhee WT, You SH, Kim SK, Lee SY. Troublesome occipital neuralgia developed by $\mathrm{C} 1-\mathrm{C} 2$ harms construct. J Korean Neurosurg Soc 2008;43:111-3.

21. Jin GX, Wang H, Li L, Cui SQ, Duan JZ. C1 posterior arch crossing screw fixation for atlantoaxial joint instability. Spine (Phila Pa 1976) 2013;38:E1397-404.

22. Guo-Xin J, Huan W. Unilateral C-1 posterior arch screws and C-2 laminar screws combined with a 1-side C1-2 pedicle screw system as salvage fixation for atlantoaxial instability. J Neurosurg Spine 2015 Oct 30 [Epub]. http://doi.org/10.3171/2015.4.spine14517. 